\title{
AVALIAÇÃO NA EDUCAÇÃO FÍSICA ESCOLAR: UMA ANÁLISE A PARTIR DO MODELO DE INTELIGÊNCIA MOTORA
}

\author{
Maria Helena da Silva Ramalho \\ Universidade do Estado de Santa Catarina, Florianópolis, Santa Catarina, Brasil \\ Caroline Regina de Almeida \\ Faculdade da Serra Gaúcha, Caxias do Sul, Rio Grande do Sul, Brasil \\ Zenite Machado \\ Universidade do Estado de Santa Catarina, Florianópolis, Santa Catarina, Brasil \\ João Otacílio Libardoni dos Santos \\ Universidade do Estado de Santa Catarina, Florianópolis, Santa Catarina, Brasil \\ Glauber Carvalho Nobre \\ Universidade do Estado de Santa Catarina, Florianópolis, Santa Catarina, Brasil
}

\section{Resumo}

O objetivo deste estudo descritivo-interpretativo é identificar elementos que constituem os Planos de Ensino e verificar os critérios e indicadores da avaliação dos estudantes de $6^{\circ}$ ao $9^{\circ}$ ano do ensino fundamental, de sete instituições municipais de Farroupilha-RS, analisando sua coerência. Participaram cinco professores do sexo feminino, seis do sexo masculino, com idades entre 19 e 51 anos. Estes forneceram seus Planos de Ensino e responderam a um questionário de questões abertas. A competência físico-cinestésica mostrou-se preponderante nas avaliações. Observou-se uma tendência em avaliações práticas e teóricas diárias, evidenciando o produto e processo da aprendizagem. Contudo, não encontramos coerência dos critérios e indicadores de avaliação com os conteúdos ministrados descritos nos Planos de Ensino.

Palavras-chave: Avaliação. Educação Física Escolar.

\section{Introdução}

pós inúmeros estudos e discussões a respeito da avaliação no
decorrer da história, as práticas avaliativas foram sendo adapta-
das às necessidades e particularidades de cada sistema de ensino. Tal-
vez seja esse um dos motivos pelos quais os professores têm buscado
maneiras e parâmetros de avaliação que amenizem o caráter subjetivo
do processo avaliativo (MAUAD, 2003). Ao deslocar o processo de
avaliação para o campo da Educação Física, Gallahue (2008) enfatiza 
que ela é um aspecto importante de qualquer programa de Educação Física porque ajuda os professores a medirem o nível presente da capacidade dos alunos, o progresso dos mesmos e sua própria eficácia no ensino. A avaliação é o meio auxiliar do processo de aprender, que acompanha o crescimento e o desenvolvimento do aluno, no sentido de avanços que devem ser feitos na direção de padrões que ele precisa ultrapassar para vencer etapas no percurso de sua vida escolar (SILVA, 1999).

A avaliação na escola deve ser um acompanhamento de todo o processo educacional, no entanto acaba sendo sempre um objetivo do processo. Não há, então, como negar que é um dos grandes problemas que as escolas possuem e que precisa ser enfrentado para ser resolvido. Temos que estudá-la e considerá-la um fator essencial do planejamento e da ação do professor (ETCHEPARE, 2000). A avaliação realizada com os alunos, conforme Luckesi (2005) possibilita ao sistema de ensino verificar como o professor está atingindo os seus objetivos, portanto, nesta avaliação ele tem uma possibilidade de autocompreensão. Na medida em que está atento ao desenvolvimento de seus alunos, poderá, através da avaliação da aprendizagem, verificar o quanto o seu trabalho está sendo eficiente e que desvios estão ocorrendo. O aluno, por sua vez, poderá estar permanentemente descobrindo em que nível de aprendizagem se encontra, dentro da sua atividade escolar, adquirindo consciência de seus limites e das necessidades de avanço.

A aprendizagem pode ser vista como um processo - como aprendemos - e/ou como um produto - o que aprendemos -, que são os resultados e as capacidades que desenvolvemos para aprender cada vez mais e melhor (OLIVEIRA, 1995). O cuidado de avaliar não só o produto e sim o processo de aprendizagem do aluno é fundamental. Gallahue (2008) descreve ainda que a forma, o processo exerce, de fato, alguma influência sobre a performance, o produto, mas nós não sabemos, na verdade, o quanto a performance está relacionada à forma correta. Seja qual for o objetivo do conhecimento em questão, os processos de ensino e aprendizagem devem considerar as características dos alunos em todas as suas dimensões: cognitiva, corporal, afetiva, ética, estética, de relação interpessoal e inserção social (CONFEF, 2002).

Para que a avaliação cumpra sua função deverá ser executada com certo rigor técnico, o que implica algumas exigências. Por exemplo, 
que os instrumentos de avaliação sejam elaborados, executados e aplicados levando-se em conta os princípios que se seguem (LUCKESI, 2005). Para serem adequados, os instrumentos deverão: medir resultados de aprendizagem claramente definidos, que estejam em harmonia com os objetivos instrucionais; medir uma amostra adequada dos resultados de aprendizagem e o conteúdo da matéria incluída na instrução; conter os tipos de itens que são mais adequados para medir os resultados de aprendizagem desejados; ser planejados para se ajustar aos usos particulares a serem feitos dos resultados; ser construídos tão fidedignos quanto possível e, em consequência, ser interpretados com cautela; ser utilizados para melhorar a aprendizagem do estudante e do sistema de ensino (LUCKESI, 2005). Kunz (2004) relata que para o professor obter o controle e avaliar a aprendizagem dos alunos, ele precisa de auxílio, e nada é encontrado de muito concreto nas diretrizes, que apenas apresentam algumas indicações genéricas com relação à avaliação do processo de ensino global - de modo especial para o sucesso. É com base nestas orientações genéricas que ele precisa medir e avaliar melhor o rendimento do aluno.

Sobre os critérios de avaliação, Kunz (2004) descreve que os mesmos indicados para o professor controlar e avaliar a aprendizagem do aluno no ensino entram em contradição com as exigências de uma avaliação no aspecto global. Os critérios lembram claramente um processo de avaliação orientado apenas para o produto final; ainda que nas mesmas sugestões, sobre a temática da avaliação, seja indicada a observação do aluno como centro da avaliação e não o seu rendimento. Nesse sentido, a avaliação de competências pode ser realizada por diferentes instrumentos, que por muitas vezes devem ser construídos para este fim. Assim, o conhecimento do processo de construção e validação de instrumentos e escalas passa a ser pertinente (TKAC, 2004).

Diante dessas discussões e preocupações sobre o processo avaliativo na disciplina de Educação Física escolar, o presente estudo buscou verificar se existe coerência entre os Planos de Ensino de Educação Física e os critérios e indicadores utilizados pelos professores na avaliação dos estudantes de $6^{\circ}$ ao $9^{\circ}$ ano). O objetivo específico da análise é identificar os elementos que constituem o Plano de Ensino explicitado pelos professores e verificar os critérios e indicadores nele apresentados no tópico "avaliação". 


\section{Metodologia}

A metodologia utilizada para o tema proposto baseou-se na abordagem qualitativa descritiva. $O$ trabalho apresenta a descrição da coerência entre os Planos de Ensino da Educação Física escolar e os critérios e indicadores utilizados pelos professores na avaliação dos estudantes de $6^{\circ}$ ao $9^{\circ}$ ano do ensino fundamental, de sete instituições municipais de ensino da cidade de Farroupilha-RS, contexto da investigação. Participaram do estudo onze professores, sendo cinco do sexo feminino e seis do sexo masculino, de diferentes faixas etárias: entre 19 e 51 anos. Nove sujeitos do estudo possuem nível superior completo, dois têm nível superior incompleto. 64\% possuem especialização. O tempo de atividade dos pesquisados na Educação Física escolar variou de dois meses a 24 anos.

$\mathrm{O}$ instrumento de coleta de dados utilizado foi um questionário com questões abertas e uma matriz para avaliação dos Planos de Ensino dos professores integrantes da pesquisa. Inicialmente foi realizado um levantamento junto à Secretaria Municipal de Educação, Cultura e Desporto (SMECD) da cidade de Farroupilha-RS, com o fim de verificar a quantidade de escolas do município, de $6^{\circ}$ ao $9^{\circ}$ ano, e o número de profissionais da área de Educação Física que trabalha nessas instituições. Após esse procedimento o instrumento foi entregue e recebido via Secretaria Municipal de Educação, Cultura e Desporto (SMECD), que mediou o estudo enviando as questões para os professores.

Para analisar as respostas dos questionários, baseamo-nos no Paradigma da Inteligência Motora de Krebs (2000), em estudos de autores que enfatizam o processo e produto do aprendizado, e nos critérios e indicadores utilizados pelos professores na avaliação dos estudantes em sua totalidade. Separamos as questões em categorias interpretadas a partir da análise de conteúdo (BARDIN, 1995), para melhor observar a coerência e objetivo dos professores no quesito avaliação.

\section{Resultados e discussão}

Relata Etchepare (2000) que raramente encontramos um professor que não se preocupa com a avaliação. Isso porque avaliar, segundo o autor, no que se refere a ensino e aprendizagem, é uma tarefa cuja importância é comparável à complexidade e dificuldade que lhe são ine- 
rentes. O professor precisa tomar muitas decisões quanto a conteúdos, objetivos, procedimentos adequados e instrumentos de medidas. Sobre essa temática o presente estudo descreve a forma como os professores avaliam seus alunos de $6^{\circ}$ ao $9^{\circ}$ ano do ensino fundamental, dividindo-a em categorias: observação, avaliação teórica e prática, avaliação comportamental como participação, interesse etc. A tendência dos professores, conforme representado em suas falas, é avaliar segundo quesitos de observação, avaliações teóricas e avaliações práticas.

Nesse sentido, ressaltam Lüdke e Mediano (1992), citados por Betti e Zuliani (2002), há necessidade de se levar em conta tanto os processos evolutivos quanto as aprendizagens específicas. A questão relevante nas avaliações práticas, afirmam os autores, é descobrir, no progresso do aluno, o que dependeu de processos de maturação relativamente espontâneos e o que foi fruto da intervenção do professor. Esse é um importante ponto a ser considerado pela Educação Física, pois, se um aluno é capaz de saltar mais hoje do que meses atrás, essa melhoria seria atribuída a fatores de crescimento e desenvolvimento físico ou a um refinamento da habilidade de saltar, adquirido nas situações de aprendizagem oferecidas nas aulas? - questiona-se.

Lüdke e Mediano (1992), citados por Betti e Zuliani (2002), nos mostram que respostas precisas demandam ainda muita investigação científica; contudo, é certo que, quanto mais uma habilidade motora depende do ambiente cultural e de oportunidades específicas de prática para desenvolver-se, mais nos aproximamos dos fatores de aprendizagem. No entanto, em nenhum momento no presente estudo, os professores referem-se às melhorias observadas na aquisição ou refinamento das habilidades motoras. Realizando uma análise conforme as três competências de Krebs (2000), podemos verificar que a tendência dos professores da disciplina de Educação Física é a avaliação do desempenho físico dos estudantes, o qual representa a competência físico-cinestésica. A competência percepto-cognitiva teve uma grande relevância nos quesitos de avaliação, ficando logo após a primeira categoria. Na competência físico-cinestésica, a aprendizagem perceptomotora e a cognitiva auxiliam no estabelecimento e refinamento da sensibilidade do indivíduo para perceber o mundo através do movimento e da habilidade de pensar, raciocinar e agir (GALLAHUE, 2003). Já na competência percepto-cognitiva, o desenvolvimento da capacidade do jogador, de pensar e resolver eficientemente qualquer 
situação de jogo, denota a formação da "inteligência operacional" (TKAC, 2004). Essa característica da personalidade do jogador é uma consequência do processo de instrução, com base na formação do hábito de pensar (antecipar, identificar e decidir) e de escolher oportuna e inteligentemente a melhor solução numa grande variedade de ações táticas guardadas na memória. Kunz (2004) afirma que os critérios indicados para a avaliação do rendimento do aluno são apenas dois: progresso de rendimento e participação ativa do aluno em aula, com o que, praticamente se inviabiliza a sugestão - que acompanha estes critérios - de que o professor considere, no planejamento de suas avaliações, os aspectos globais da atuação do aluno, ou seja, o aspecto psicomotor, afetivo e cognitivo. Neste caso faltou alguns professores avaliarem seus alunos no quesito afetivo.

Para dar continuidade à análise das questões que apresentavam os mesmos objetivos, passamos a analisar os critérios utilizados pelos educadores na avaliação de seus alunos dividindo as respostas obtidas em quatro categorias: avaliação física, comportamental, prática e teórica. A tendência de respostas foi a categoria comportamental como critério de avaliação. Realizando a análise nas três competências, o resultado encontrado foi a tendência de respostas em duas competências: a físico-cinestésica e a socioemocional. Dentro da competência socioemocional, o aprendizado social - em que crianças e jovens aprendem certos tipos de comportamento convivendo com outras pessoas, observando e interiorizando esses comportamentos - constitui um dos fatores mais relevantes no desenvolvimento, cita Krebs (2000). Na mesma competência, o crescimento socioafetivo é o processo de aprendizagem que amplia a capacidade da criança de agir, interagir e reagir efetivamente com outras pessoas, bem como consigo mesma (GALLAHUE, 2003).

A proposta defendida por Gallahue e Ozmun (2003) é uma Educação Física desenvolvimentista, que contemple não apenas os domínios do comportamento humano (cognitivo, afetivo ou psicomotor), em detrimento dos outros, pois isso levaria a um desequilíbrio do processo de desenvolvimento do aluno e a práticas educacionais encaminhadas para o resultado. Essa abordagem, relatam os autores, enfatizará um indivíduo em constante e direta interação com os elementos dinâmicos de seus contextos de vida, harmonizando de forma indissociável seus atributos motores, cognitivos e sociais. No presente estudo, a análise indica que os professores investigados não deram tanta impor- 
tância ao domínio cognitivo, revelando, portanto, uma situação de possível falta de harmonia entre as práticas educativas e o processo de desenvolvimento global do aluno.

Os indicadores utilizados pelos professores em suas avaliações demonstram que nenhum deles faz uma relação coerente entre os indicadores e os conteúdos desenvolvidos. As respostas foram dadas sem objetividade e clareza. Nessa categoria, as falas dos professores traduzem a incoerência entre o Plano de Ensino e a realização do processo de avaliação.

A combinação dos indicadores quantitativos e qualitativos compõe, conjuntamente, a critério de professores e alunos, a nota atribuída a exercícios, provas, relatórios, arguições, projetos, pesquisas, redações, monografias. Ainda sobre a questão de avaliação, analisamos os critérios utilizados pelos educadores. Os mais utilizados, segundo as respostas emitidas, foram: a avaliação prática e a comportamental (participação, boa vontade, interesse etc.).

A respeito de critérios utilizados pelos professores, especialistas em avaliação apontam que os mesmos utilizam critérios informais, como encontrado nas análises das respostas dadas pelos professores questionados, que avaliam em seus alunos o interesse, a capacidade geral, o comportamento, a qualidade e limpeza de trabalho etc, (ENGUITA, 1989). A avaliação das habilidades dos estudantes foi analisada em categorias de observação. Observamos que a tendência dos professores é realizar a avaliação da aprendizagem do aluno não como um processo, mas como um produto. A realidade encontrada no presente estudo é discutida por Lima (1995), citado por Etchepare (2000): "A escola hoje está reduzida ao processo de avaliação e tão vazia de proposta pedagógica que não vemos melhor objeto do que o estudo do processo de avaliação". A grande maioria das escolas brasileiras é adepta aos princípios quantitativos, oferecendo-nos as provas e testes como instrumentos que, teoricamente, avaliam o processo pedagógico (ETCHEPARE, 2000).

Os conteúdos desenvolvidos e avaliados pelos professores durante as aulas, na disciplina de Educação Física, evidenciaram que a tendência é trabalhar conteúdos como esportes individuais e coletivos, e esportes juntamente com dança e ginástica formativa. Comparando os conteúdos apresentados nos Planos de Ensino com os descritos pelos professores, encontramos contradições, por exemplo, em relação à recreação, ginástica formativa e dança. Dos onze questionados, apenas 
um descreveu os conteúdos conforme o Plano de Ensino. Os outros apresentaram a dança, que não constava em seus Planos de Ensino, e não indicaram a ginástica formativa e recreação descritas nos mesmos. Shigunov, V. et al, citados por Shigunov Neto e Shigunov (2002), descrevem que o planejamento é essencial em todas as situações da escola, pois facilita ao professor ordenar suas atividades e objetivos. Nessa perspectiva, Nasário (1999) comenta que "deve-se entender que é o planejamento que orienta e conduz, de forma organizada, as ações dos conteúdos mais perto da concretização dos objetivos propostos" (p.65).

Os esportes individuais e coletivos são os conteúdos mais ministrados pelos professores nas instituições de ensino de Farroupilha-RS. Ao analisar os critérios e conteúdos, não encontramos coerência entre os mesmos, ou seja, as avaliações práticas não foram descritas conforme os fundamentos trabalhados nos esportes. Os professores apenas generalizaram as respostas, não identificando o que realmente avaliam em seus alunos. Faz-se necessário que o professor utilize estratégias avaliativas de acordo tanto com os objetivos específicos (aprendizagem de habilidades motoras básicas e especializadas, jogos etc.), quanto com a finalidade geral de integrar o aluno na cultura corporal de movimento, formando o cidadão que vai produzi-la, reproduzi-la e transformá-la, instrumentalizando-o para usufruir o jogo, o esporte, a dança e a ginástica em benefício de sua qualidade de vida (BETTI \& ZULIANI, 2005).

É preciso que o professor considere a amplitude da avaliação: o que avaliar no aluno? (GIMENO, 1988). As concepções mais progressistas propõem a avaliação da totalidade do aluno e sugerem um rendimento ideal, determinado pelos conteúdos legitimados institucionalmente no currículo e pelo conceito legitimado de cultura a transmitir. Por essa visão, descreve o autor, o rendimento ideal não é só intelectual, mas considera aspectos amplos da personalidade, como as facetas afetivas, sociais e corporais.

\section{Conclusão}

A partir das falas dos professores, analisadas conforme o Paradigma da Inteligência Motora de Krebs (2001) constatou-se que a maioria deles avalia seus alunos dentro da competência físico-cinestésico e o desempenho dos estudantes é o principal quesito de avaliação. Veri- 
ficou-se igualmente que os critérios adotados não são coerentes com os conteúdos ministrados. O que se evidencia neste estudo, é a falta de observação, na prática pedagógica, da inter-relação entre os objetivos (gerais e específicos), os conteúdos, os procedimentos ou estratégias, os recursos e a avaliação, sugerida por Scarpatto (2007).

As avaliações realizadas pelos professores são orientadas para o produto, embora as estratégias de avaliação orientada para o processo foram incluídas em seus planos de ensino. Não encontramos coerência entre os critérios e indicadores de avaliação e os conteúdos apresentados pelos professores em seus Planos de Ensino.

Contudo esse estudo retrata a realidade do processo de avaliação, apontando a dificuldade dos profissionais em realizar uma avaliação pautada em instrumentos bem elaborados que considerem o estudante em um todo. Estas tarefas não são difíceis de organizar, porém requer um maior auxílio teórico e pedagógico aos professores, devendo ser investigado o motivo pelo qual não vem sendo efetivado.

Assesment in school physical education: an analysis starting from motor intelligence model

\begin{abstract}
This descriptive- interpretive study examines consistency between the Plan of Education and the criteria and indicators used by teachers in public schools of Farroupilha-RS. The specific objective is to identify the elements of the Plan of Education explained by educators and to verify the criteria and indicators presented in these topic for the evaluation of students from fifth to eight grade of sete (seven) municipal institutions. Eleven teachers were asked, and of these, five females and six males, aged between 19 (nineteen) and 51 (fifty-one). The instrument used to collect data was a questionnaire with open questions and outline of the teachers in the study. It was concluded that the majority of respondents asses their students by emphasizing the physical kinesthetic competence. The study also showed a trend in assessment practice and theoretical evaluation, that is, the product of learning. We realized the speeches of educators who are held daily assessments, highlighting the process. However, we found no consistency of criteria and indicators for evaluation with the contents taught described in the Teaching Plan of the teachers.
\end{abstract}

Keywords: Assessment. Physical Education. School. 
Evaluación en educación física escolar: un análisis a partir del modelo de inteligencia motriz

\begin{abstract}
Resumen
Este estudio descriptivo-interpretativo hace un análisis de la coherencia entre el Plan de Enseñanza y los criterios e indicadores usados por los profesores en las escuelas municipales de Farroupilha, RS. El objetivo específico es identificar los elementos que constituyen el Plan de Enseñanza explicitados por los educadores y verificar los criterios e indicadores presentados por estos en el tópico sobre la evaluación de los estudiantes del $5^{\circ}$ al $8^{\circ}$ grado de siete instituciones municipales. Se hizo la encuesta a onze profesores, de los cuales cinco eran del sexo femenino y seis del masculino, con edades entre los 19 y los 51 años. El instrumento utilizado en la recolección de los datos fue un cuestionario con preguntas abiertas y Planes de Enseñanza de los propios profesores integrantes de la encuesta. Se llegó a la conclusión de que la mayoría de los entrevistados evalúa a sus alumnos enfatizando la capacidad físico-cinética de ellos. El trabajo también presentó una tendencia a la evaluación práctica y teórica, o sea, el producto del aprendizaje. Se ha percibido, por el habla de los educadores, que se realizan las evaluaciones a diario, lo que enfatiza el proceso. Sin embargo, no hemos encontrado coherencia entre los criterios e indicadores de evaluación y los contenidos suministrados, constantes de los Planes de Enseñanza de los profesores.
\end{abstract}

Palabras clave: Evaluación. Educación Física. Escolar

\title{
Referências
}

BRASIL, Ministério da Educação e do Desporto, Secretaria de Educação Fundamental. Parâmetros Curriculares Nacionais $-3^{\mathbf{o}}$ e $\mathbf{4}^{\mathbf{o}}$ ciclos do Ensino Fundamental: Educação Física. Brasília: MEC, SEF, 1998.

BRASIL. Secretaria de Educação Básica. Orientações curriculares para o ensino médio: linguagens, códigos e suas tecnologias. Brasília: ME/SEB, 2006. Disponível em: <http://portal.mec.gov.br/seb/arquivos/pdf/book_volume_01_internet.pdf $>$. Acesso em: 13 out. 2011.

CASTELlANi FILHO, L. et al. Metodologia do Ensino da Educação Física. São Paulo: Cortez, 2009.

CENSO ESCOLAR, 2010. Disponível em: <www.educacenso.inep.gov.br>. Acesso em: 12 mar. 2011.

CHERVEL, A. História das disciplinas escolares: reflexões de um campo de pesquisa. Revista Teoria \& Educação (2). Porto Alegre: Pannonica, 1990. 
COLL, C. Psicologia e Currículo: uma aproximação psicopedagógica à elaboração do currículo escolar. São Paulo: Ática, 1997.

DAÓLIO, J. Educação Física Brasileira: autores e atores da década de 1980. Campinas: Papirus, 1998.

FREITAS, L. C. Crítica da organização do processo de trabalho pedagógico e da didática. Campinas: Papirus, 1995.

ESTADO DA BAHIA. Educação: Caminho para a construção da cidadania. Educação Física. Diretrizes curriculares para o ensino fundamental, 1994.

. Orientações curriculares estaduais para o ensino médio. Área de Linguagem, Código e suas tecnologias. 2005.

KUNZ, E. Transformação didático-pedagógica do esporte. Ijuí: Unijuí, 1994.

MINAYO, M. C. S. (Org.). Pesquisa social: teoria, método e criatividade. São Paulo: Vozes, 2000.

PIRES, R. G. Educação Física na Bahia: cenas e flashes de uma história. Salvador: Arcádia, 2008.

PISTRAK, M. (Org.). A escola-comuna. São Paulo: Expressão popular, 2010.

SÃO PAULO (Estado). Secretaria da Educação. Proposta curricular do Estado de São Paulo: Educação Física. São Paulo: SEE, 2008. Disponível em: <http://www.rededosaber.sp.gov.br/portais/Portals/18/arquivos/Prop_EDF_COMP_red_md_20_03.pdf $>$. Acesso em: 13 out. 2011.

SOUZA, J. F. Uma pedagogia da revolução. São Paulo: Cortez/Autores Associados, 1987.

TAFFAREL, C. Z. Educação Física: referências curriculares para a rede pública do Estado da Bahia. Salvador: Mimeo, 2010. 
Recebido em: 31/05/2011

Revisado em: 23/09/2011

Aprovado em: 27/01/2012

\section{Endereço para correspondência}

glauber_nobre@hotmail.com

Glauber Carvalho Nobre

Universidade do Estado de Santa Catarina

Centro de Educação Física e Desportos.

Paschoal Simone 358

Coqueiros

88080-350 - Florianopolis, SC - Brasil 